\title{
Influence of limestone flour on properties of expanded clay concrete
}

\author{
Vladimir Belov* and Pavel Kuliaev \\ Tver State Technical University, Civil Construction Department, 22, Af. Nikitin Quay, Tver, Russia
}

\begin{abstract}
The article enlightens the influence of limestone flour as a fine mineral additive on the physical and mechanical characteristics of expanded clay concrete. It was determined that when this component is applied in an amount of $5 \%$, the strength increases by $16 \%$, and in combination with a hyperplasticizer- by $25 \%$ compared to a non-additive specimen. It is also worth noting that when the content of limestone flour is $10 \%$ by weight of cement, the performance values do not decrease.
\end{abstract}

\section{Experiment}

\subsection{Introduction}

In concrete production, cement, one of the most expensive components, is used as a binder. Therefore, in order to save the cost of construction, we have to look for alternative options, one of which is the use of industrial wastes [1]. The accumulated scientific and practical experience of using these materials in Russia and abroad allows us to consider them as valuable raw resources for the production of building materials [1].

The available in-depth theoretical research in the field ofmining and processing waste provides a basis for asserting that the use of these resources is applicable to optimize the processes of structure formation of expanded clay concrete mixtures by initiating the formation of hydrate compounds [2].

One of the positive factors of their introduction is to increase the strength characteristics and reduce the permeability of composites in the construction of buildings where there are increased requirements for strength (for example, in higher and large-span buildings) [3].

Many studies put forward the use of carbonate additives (in particular, limestone flour), which help to reduce the delamination and water segregation of concrete mixtures; increase their water-holding capacity and uniformity; reduce shrinkage and heat release of concrete, and also improve their water, frost and acid resistance [3]. In [4], it was shown that the beneficial effect of limestone additives is observed when it is introduced up to $15 \%$ of the binder weight. Also, studies [3] on a cement-sand solution showed an increase in strength by $15-19 \%$ compared to the control sample with the degree of substitution of Portland cement with an additive of $30-45 \%$. However, these experiments were performed using the hyperplasticizer melflux $1641 \mathrm{~F}$, introduced in an amount of $0.3 \%$ by weight of cement [5].

\footnotetext{
*Vladimir Belov: vladim-bel@yandex.ru
} 
Thus, the purpose of this work is to study the effect of limestone flour as a mineral additive in a fine-dispersed form in a complex additive with a hyperplasticizer on the physical and mechanical characteristics of expanded clay concrete to save the binder part without reducing performance characteristics

\subsection{Materials}

In this paper, studies were performed on the influence of limestone flour on expanded clay concrete properties. They were carried out using Portland cement of JSC "Novoroscement" brand PC 500-D0 according to the Standard 10178-85 (cement activity 51.2 MPa), quartz sand (modulus of size $\mathrm{MK}=1.9-2.0$ ), expanded clay sand of the $0-5$ fraction, limestone flour and hyperplasticizer melflux 5581F.

\section{Test results}

To obtain light concrete made on the basis of aggregate, a combined binder is used, which consists of cement and limestone flour in a given ratio (Table 1).

Table 1. Test results

\begin{tabular}{|c|c|c|c|c|}
\hline № & Cement, $\%$ & Limestone flower, $\%$ & HP, $\%$ & Strength in compression, MPa \\
\hline 1 & 100 & 0 & 0,0 & 17,1 \\
\hline 2 & 95 & 5 & 0,0 & 20,7 \\
\hline 3 & 90 & 10 & 0,0 & 16,7 \\
\hline 4 & 85 & 15 & 0,0 & 14,9 \\
\hline 5 & 100 & 0 & 0,3 & 20,5 \\
\hline 6 & 95 & 5 & 0,3 & 23,9 \\
\hline 7 & 90 & 10 & 0,3 & 19,2 \\
\hline 8 & 85 & 15 & 0,3 & 17,6 \\
\hline
\end{tabular}

The use of limestone powder is aimed at saving the binder without reducing the structural characteristics. The introduction of a hyperplasticizer with this binding part leads to an increase in structural characteristics, such as strength, density, thereby reducing the porosity of the concrete obtained.

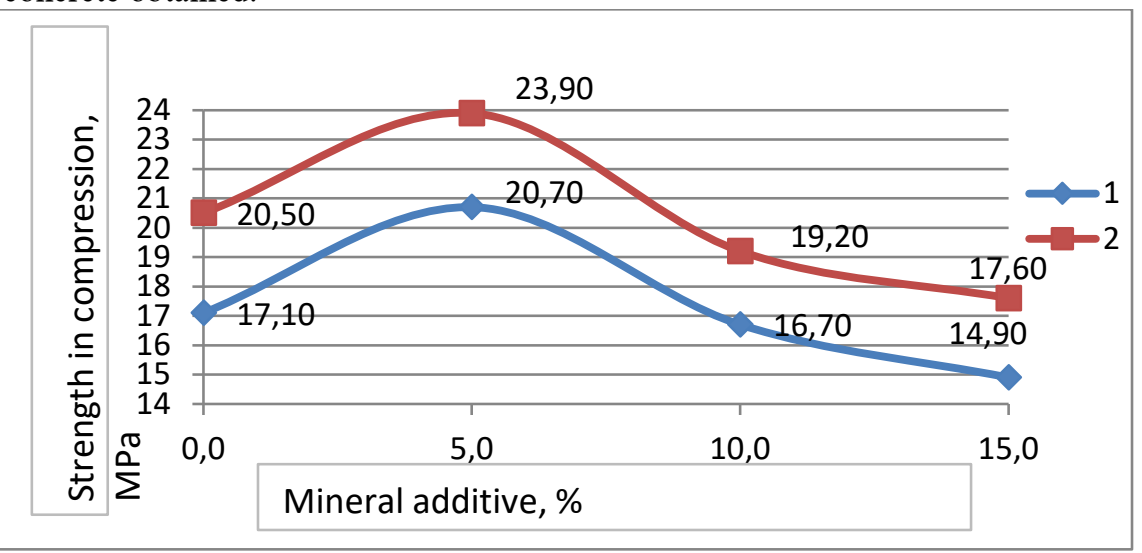

Fig. 1. Dependence of the compressive strength of samples on the amount of additive 1 hyperplasticizer melflux $5581 \mathrm{~F}$ is $0 \%$ by weight of cement 2 -hyperplasticizer melflux $5581 \mathrm{~F}$ is $0.5 \%$ by weight of cement 


\section{Summary and prospects}

According to the data presented in Fig.1, the greatest increase in strength is achieved with the introduction of $5 \%$ limestone flour. At the same time, the strength increases by $16 \%$ compared to the characteristics of a non-additive sample. The mineral additive in combination with the hyperplasticizer is also active at concentrations of $5 \%$, while the strength increases by $25 \%$ of the strength of the control mixture. It is also worth noting that with a content of $10 \%$ of limestone flour, the strength indicators practically do not decrease in comparison with the initial data. This shows that it is possible to save cement by partially replacing it with limestone flour. The dependences of the compressive strength of the tested samples show that with the maximum introduction of a mineral additive, the strength decreases.

\section{Conclusion}

In the course of investigations, the introduction of mineral additive in lightweight aggregate mix was made, which leads to optimization concrete parameters. This additive in the amount of $10 \%$ does not reduce the strength characteristics of concrete, increases water and corrosion resistance, and does not reduce the effectiveness of the hyperplasticizer. This fact allows us to talk about the partial replacement of cement with limestone flour, performing one of the important tasks - saving the binder.

\section{References}

1 Morozova N. N., kays H. A. Rheological characteristics of modified mineral additives for light concrete / Modern scientific research and innovation. 2015. № 10. P. 7-18.

2 Teryanik V. V., Shpoltakov V. I. method for obtaining light composite elements and their properties / Concrete and reinforced concrete. 2014. № 3. P. 8-10.

3 Timashev V. V. Properties of cements with carbonate additives / Cement and its application. 2013. № 10. P. 10-12.

4 Efremenko, A. S. Light high-strength concrete based on finely ground composite binders / Abstract of the theses for the degree of candidate of technical Sciences // Ulan-Ude 2013.P. 24.

5 Shatov A. N. High-strength concrete. Available methods of chemical modification / technology of concrete. 2012. № 9-10. P. 9-11. 